Jurnal Inkofar * Volume 1 No. 2 Desember 2019 * ISSN: 2615-3645 (Print) / 2581-2920 (Online)

Tersedia secara online di: http://www.politeknikmeta.ac.id/meta/ojs/

\title{
IMPLEMENTASI METODE SIMPLE ADDITIVE WEIGHTING UNTUK MENENTUKAN KARYAWAN TELADAN DI PT SMART SOLUTION BEKASI
}

\author{
Cepi Cahyadi ${ }^{1}$, Manase Sahat H Simarangkir ${ }^{2}$ \\ ${ }^{1}$ Sistem Informasi / Program S1 / STMIK Nusa Mandiri / cepi.ccd@nusamandiri.ac.id \\ ${ }^{2}$ Teknik Komputer / Program D3 / Politeknik Meta Industri Cikarang / \\ manasemalo@politeknikmeta.ac.id
}

\begin{abstract}
PT Smart Solution has a lot of outstanding employees, but when it comes to the selection process of model employees is very difficult, because each employee has different abilities, the decision making to choose model employees is based on the subjectivity of the different department heads concerned. So many complain about the decision to choose model employees who are not well targeted. With the existing problems, the researchers tried to change the old system by implementing a decision support system using the Simple Additive Weighting method. The basic concept of the Simple Additive Weighting method is to find a weighted sum of the performance ratings for each alternative on all attributes. The criterion that determines the exemplary employee at PT Smart Solution is performance evaluation, years of service and attitudes. A greater value will indicate that the alternative is chosen. In the case of determining a model employee at PT Smart Solution, the results of the assessment use the Simple Additive Weighting method by using a previous assessment that will see the difference during the ranking process.
\end{abstract}

Keywords: Decision Support Systems, Simple Additive Weighting, Exemplary Employees.

\begin{abstract}
ABSTRAK
PT Smart Solution memiliki banyak karyawan yang berprestasi, tetapi ketika melakukan proses seleksi karyawan teladan sangat sulit, karena setiap karyawan memiliki kemampuan yang berbeda-beda, Pengambilan keputusan untuk memilih karyawan teladan melainkan atas dasar subyektifitas kepala bagian departemen yang terkait yang berbeda-beda. Sehingga banyak yang mengajukan komplain tentang keputusan terpilihnya karyawan teladan yang kurang tepat sasaran. Dengan permasalahan yang ada maka peneliti mencoba merubah sistem yang lama dengan menerapkan sistem pendukung keputusan menggunakan metode Simple Additive Weighting. Konsep dasar metode Simple Additive Weighting adalah mencari penjumlahan terbobot dari rating kinerja pada setiap alternatif pada semua atribut.Kriteria yang menjadi penentuan karyawan teladan di PT Smart Solutionadalah penilaian kinerja, masa kerja dan Sikap. Nilai yang lebih besar akan mengindikasikan bahwa alternative lebih terpilih. Pada kasus penentuan Karyawan teladan di PT Smart Solution hasil dari penilaian menggunakan metode Simple Additive Weighting dengan menggunakan penilaian yang sebelumnya akan terlihat perbedaannya pada saat proses perangkingan.

Kata Kunci: Sistem Penunjang Keputusan, Simple Additive Weighting, Karyawan Teladan.
\end{abstract}

\section{PENDAHULUAN}

Karyawan merupakan salah satu faktor penting dalam sebuah perusahaan atau instansi, karena dengan adanya karyawan yang memiliki standar kualifikasi perusahaan yang baik maka produktivitas perusahaan pasti akan tetap terjaga dan semakin meningkat. Oleh sebab itu sangat baik bagi suatu perusahaan memilih karyawan terbaik/teladan dan diberi penghargaan agar dapat meningkatkan kualitas karyawan dalam perusahaan.

Proses yang sedang berjalan untuk memilih salah satu karyawan untuk dijadikan karyawan teladan sangatlah sulit, karena setiap karyawan memiliki kemampuan yang berbeda-beda, Namun proses pengambilan keputusan untuk memilih karyawan teladan melainkan atas dasar subyektifitas kepala bagian departemen masing-masing. Sehingga banyak yang mengajukan komplain tentang keputusan terpilihnya karyawan teladan yang kurang tepat sasaran. Karena biasanya penilaian dilakukan hanya dengan satu atau kategori saja, dampaknya hanya akan meningkatkan persaingan dilingkungan perusahaan. 
Tujuan penelitian ini adalah membantu memberikan solusi bagi pengambil keputusan yang didukung dengan metode Simple Additive Weighting.

Manfaat penelitian ini akan mempermudah dalam menentukan pencarian karyawan teladan dan akan mempercepat penghitungan nilai untuk menentukan karyawan teladan di PT Smart Solution Bekasi.

\section{LANDASAN TEORI}

\subsection{Penelitian Terdahulu}

Pada penelitian sebelumnya yang dilakukan oleh Desyanti (2016) Metode Simple Additive Weighting dapat memecahkan permasalahan yang kompleks melalui pendekatansistem dan pengintegrasian secara deduktif sehingga menentukan karyawan teladan dapat terlaksana dengan objektif.

Pada penelitian sebelumnya di lakukan oleh Rina Endarti, Andriani Kusumaningrum, Wawan Laksito YS (2015), Sistem penunjang keputusan untuk penilaian kinerja pegawai menggunakan metode Simple Additive Weighting. pada proses penilaian kinerja pegawai lebih efesien sehingga pihak perusahaan lebih cepat dalam proses pengambilan keputusan yang bersifat objektif.

\subsection{Penilaian Kinerja}

Menurut Gary Dessler (2005:310) Penilaian Kinerja adalah merupakan upaya membandingkan prestasi aktual karyawan denganprestasi kerja dengan yang diharapkan darinya.

\subsection{Sistem Keputusan Pendukung}

Menurut Latif et al. (2018:3) menyatakan sistem pendukung keputusan adalah suatu sistem informasi spesifik yang ditujukan untuk membantu manajemen dalam mengambil keputusan yang berkaitan dengan persoalan yang bersifat semi terstruktur.

Menurut Sutabri (2012:61) menyatakan sistem pendukung keputusan adalah suatu sistem informasi untuk membantu manajer level menengah untuk proses pengambilan keputusan setengah terstuktur supaya lebih efektif dengan menggunakan model-model analisis dan data yang tersedia.

\subsection{Simple Additive Weighting}

Menurut (Nofriansyah, 2014:11) Metode simple additive weighting membutuhkan proses normalisasi matriks keputusan $(x)$ ke suatu skala yang didapat diperbandingkan dengan semua rating alternative yang ada.

\section{METODE PENELITIAN}

\subsection{Metode simple additive weighting}

Metode ini sering dikenal dengan istilah metode penjumlahan terbobot. Konsep dasar metode simple additive weighting adalah mencari penjumlahan terbobot dari rating kinerja pada setiap alternatif pada semua atribut. Metode simple additive weighting disarankan untuk menyelesaikan masalah penyeleksian dalam sistem pengambilan keputusan multi proses. Metode simple additive weighting merupakan metode yang banyak digunakan dalam pengambilan keputusan yang memiliki banyak atribut. Metode simple additive weighting membutuhkan proses normalisasi matriks keputusan $(x) \mathrm{ke}$ suatu skala yang didapat diperbandingkan dengan semua rating alternative yang ada. (Nofriansyah, 2014:11)

Formula untuk melakukan normalisasi tersebut adalah sebagai berikut:

$$
r_{i j}=\left\{\begin{array}{lr}
\frac{X_{i j}}{M a x X_{i j}} & \text { Jika } j \text { adalah atribut keuntungan (benefit) } \\
\frac{\text { Min } X_{i j}}{X i j} & \text { Jika } j \text { adalah atribut biaya (cost) }
\end{array}\right.
$$

Dimana dengan $\mathrm{r}_{\mathrm{ij}}$ adalah rating kinerja ternormalisasi dari alternatif $A_{i}$ pada atribut $\boldsymbol{C}_{\boldsymbol{j}}: \boldsymbol{i}=\mathbf{1 , 2} \ldots . ., \boldsymbol{m}$ danj $=1,2 . ., n$

Keterangan :

- Max $X_{i j} \quad=$ Nilai terbesar dari setiap kriteria $\mathrm{i}$

- Min $X_{i j} \quad=$ Nilai terbesar dari setiap kriteria i

- $X_{i j} \quad=$ Nilai atribut yang dimiliki dari setiap kriteria

- Benefit = Jika nilai terbesar adalah terbaik

- Cost = Jika nilai terkecil adalah terbaik 
Jurnal Inkofar * Volume 1 No. 2 Desember 2019 * ISSN: 2615-3645 (Print) / 2581-2920 (Online)

Tersedia secara online di: http://www.politeknikmeta.ac.id/meta/ojs/

$$
V_{i}=\sum_{j-1}^{n} w_{j} r_{i j}
$$

Nilai preferensi untuk setiap alternatif $(V i)$ diberikan rumus sebagai berikut:

Keterangan:

$$
\begin{array}{ll}
V_{i} & =\text { Rangking untuk setiap alternatif } \\
w_{j} & =\text { Nilai bobot rangking (dari setiap kriteria) } \\
r_{i j} & =\text { Nilai rating kinerja ternormalisasi }
\end{array}
$$

\subsection{Tahapan Penelitian}

Tahapan penelitian yang dilakukan dalam menentukan karyawan teladan pada PT Smart Solution adalah sebagai berikut:

a) Identifikasi masalah Identifikasi masalah yang akan dijadikan sebagai kriteria pokok pembahasan PT Smart Solution untuk menentukan karyawan teladan dan menerapkan perhitungan Simple Additive Weighting.

b) Studi Literatur

1. Kriteria Penilaian dalam proses penentuan karyawan teladanyang dinilai berdasarkan kriteria Penilaian Kinerja, Masa Kerja dan Sikap.

2. Bobot Penilaian perkriteria terdapat beberapa kriteria bobot dalam proses penentuan karyawan teladan agar data yang di olah sesuai dengan kebutuhan.

c) Pengumpulan data-data seperti apa yang dibutuhkan berdasarkan populasi dan sampel.

d) Pengolahan data dalam pemberian kode variable secara Metode Simple Additive Weighting.

\subsection{Intrumen Penelitian}

Kriteria yang digunakan adalah:

Tabel 1. Kriteria

\begin{tabular}{|c|l|c|}
\hline Aspek & \multicolumn{1}{|c|}{ Range } & Bobot \\
\hline Penilain & Nilai $<75$ (Tidak Baik) & 1 \\
Kinerja & Nilai 75-<80 (Perbaikan) & 2 \\
& Nilai $80-<90$ (Baik) & 3 \\
& Nilai $90-<100$ (Sangat Baik) & 4 \\
& Nilai $\geq 100$ (Istimewa) & 5 \\
\hline Masa Kerja & $0-1$ Tahun & 1 \\
& 2 Tahun & 2 \\
& 3Tahun & 3 \\
& 4Tahun & 4 \\
& $>5$ Tahun & 5 \\
\hline Sikap & Nilai $<50$ (Tidak Baik) & 1 \\
& Nilai $50-<65$ (Perbaikan) & 2 \\
& Nilai $65-<80$ (Baik) & 3 \\
& Nilai $80-<100$ (Sangat Baik) & 4 \\
& Nilai $\geq 100$ (Istimewa) & 5 \\
\hline
\end{tabular}

PT Smart Solution(2019)

Botot Preferensi (W) setiap kriteria yang akan digunakan adalah sebagai berikut:

$$
\begin{aligned}
\mathrm{W} 1 & =\text { Penilaian Kinerja }(50 \%)=0,5 \\
\mathrm{~W} 2 & =\text { Masa Kerja }(25 \%)=0,25 \\
\mathrm{~W} 3 & =\operatorname{Sikap}(25 \%)=0,25
\end{aligned}
$$

Alternative yang akan diuji adalah data dari 30 karyawan PT Smart Solution dengan maksimal kerja 5 tahun untuk 
Jurnal Inkofar * Volume 1 No. 2 Desember 2019 * ISSN: 2615-3645 (Print) / 2581-2920 (Online)

Tersedia secara online di: http://www.politeknikmeta.ac.id/meta/ojs/

Tabel 2. Alternatif Calon Karyawan Teladan

\begin{tabular}{|l|l|}
\hline $\mathbf{A 1}$ & WIRYADINATA \\
\hline $\mathbf{A 2}$ & ACHMAD SUBAGJA \\
\hline $\mathbf{A 3}$ & MUHAMMAD RAFI \\
\hline $\mathbf{A 5}$ & DWI CAHYO HADI \\
\hline $\mathbf{A 6}$ & REDE APRILLA \\
\hline $\mathbf{A 7}$ & VAZEN MUKMININ \\
\hline $\mathbf{A 8}$ & DHEWANGGA ADITYA \\
\hline $\mathbf{A 9}$ & MUHAMMAD RAIHAN \\
\hline $\mathbf{A 1 0}$ & DICKY TARUNA \\
\hline $\mathbf{A 1 1}$ & RAUZAN AULIA \\
\hline $\mathbf{A 1 2}$ & WAFA RIFQI ANAFIN \\
\hline $\mathbf{A 1 3}$ & RENALDI \\
\hline $\mathbf{A 1 4}$ & DIMAZNUGROHO \\
\hline $\mathbf{A 1 5}$ & REZKYTEGUH \\
\hline $\mathbf{A 1 6}$ & AHMAD FAQQIH \\
\hline $\mathbf{A 1 7}$ & HANI AMMARI'A \\
\hline $\mathbf{A 1 8}$ & YULITA \\
\hline $\mathbf{A 1 9}$ & INGGIT MARSELIA \\
\hline $\mathbf{A 2 0}$ & MUHAMMAD KEVIEN \\
\hline $\mathbf{A 2 1}$ & HAIKAL ARVIANSYAH \\
\hline $\mathbf{A 2 2}$ & SUKMA JAYA \\
\hline $\mathbf{A 2 3}$ & THERESIA GITA \\
\hline $\mathbf{A 2 4}$ & PUTRA EKA CAHYADI \\
\hline $\mathbf{A 2 5}$ & NABILA ADINDA \\
\hline $\mathbf{A 2 6}$ & RAVIPAHLEVI \\
\hline $\mathbf{A 2 7}$ & ARDIANDHANY \\
\hline $\mathbf{A 2 8}$ & GAGAH SAPUTRA \\
\hline $\mathbf{A 2 9}$ & GERHANA ALHILAL \\
\hline $\mathbf{A 3 0}$ & NUR WACHIDAH QUMI \\
\hline
\end{tabular}

Sumber: PT Smart Solution (2019)

Dalam penentuan karyawan teladan dengan metode Simple Additive weight berdasarkan kriteriakriteria diatas maka diperoleh data seperti table dibawah;

Tabel 3.Nilai dari masing-masing kriteria

\begin{tabular}{|c|c|c|c|}
\hline \multicolumn{4}{|c|}{ Kriteria } \\
\hline $\begin{array}{c}\text { Alternatif } \\
\text { (Karyawan) }\end{array}$ & $\begin{array}{c}\text { Penilaian } \\
\text { Kinerja }\end{array}$ & $\begin{array}{l}\text { Masa } \\
\text { Kerja }\end{array}$ & Sikap \\
\hline A1 & 92 & 0 & 100 \\
\hline $\mathrm{A} 2$ & 83 & 1 & 100 \\
\hline A3 & 110 & 1 & 100 \\
\hline A4 & 36 & 5 & 100 \\
\hline A5 & 36 & 5 & 100 \\
\hline A6 & 108 & 1 & 100 \\
\hline A7 & 90 & 1 & 100 \\
\hline A8 & 95 & 3 & 100 \\
\hline A9 & 107 & 0 & 90 \\
\hline A10 & 106 & 5 & 100 \\
\hline A11 & 106 & 1 & 100 \\
\hline A12 & 106 & 1 & 100 \\
\hline A13 & 70 & 5 & 100 \\
\hline A14 & 35 & 3 & 100 \\
\hline A15 & 95 & 5 & 75 \\
\hline A16 & 105 & 5 & 85 \\
\hline A17 & 72 & 5 & 100 \\
\hline A18 & 81 & 5 & 100 \\
\hline A19 & 93 & 5 & 100 \\
\hline A20 & 69 & 5 & 100 \\
\hline A21 & 60 & 5 & 100 \\
\hline A22 & 88 & 5 & 100 \\
\hline A23 & 92 & 3 & 100 \\
\hline A24 & 91 & 5 & 100 \\
\hline A25 & 83 & 5 & 100 \\
\hline A26 & 77 & 5 & 100 \\
\hline A27 & 34 & 5 & 100 \\
\hline A28 & 80 & 5 & 100 \\
\hline A29 & 82 & 5 & 100 \\
\hline A30 & 73 & 5 & 70 \\
\hline
\end{tabular}

Sumber: PT Smart Solution (2019) 
Penentuan rating kecocokan nilai dari masing-masing kriteria dimasukan kedalam table rating kecocokan yang telah disesuaikan dengan nilai dari tabel kriteria seperti yang ditunjukan dalam tabel

Tabel 4. Rating Kecoccokan

\begin{tabular}{|c|c|c|c|}
\hline \multicolumn{4}{|c|}{ Kriteria } \\
\hline $\begin{array}{c}\text { Alternatif } \\
\text { (Karyawan) }\end{array}$ & $\begin{array}{c}\text { Penilaian } \\
\text { Kinerja }\end{array}$ & $\begin{array}{l}\text { Masa } \\
\text { Kerja }\end{array}$ & Sikap \\
\hline $\mathrm{A} 1$ & 4 & 1 & 5 \\
\hline A2 & 3 & 1 & 5 \\
\hline A3 & 5 & 1 & 5 \\
\hline A4 & 1 & 5 & 5 \\
\hline A5 & 1 & 5 & 5 \\
\hline A6 & 5 & 1 & 5 \\
\hline A7 & 4 & 1 & 5 \\
\hline A8 & 4 & 3 & 5 \\
\hline A9 & 5 & 1 & 4 \\
\hline A10 & 5 & 5 & 5 \\
\hline A11 & 5 & 1 & 5 \\
\hline A12 & 5 & 1 & 5 \\
\hline A13 & 2 & 5 & 5 \\
\hline A14 & 1 & 3 & 5 \\
\hline A15 & 4 & 5 & 3 \\
\hline A16 & 5 & 5 & 4 \\
\hline A17 & 2 & 5 & 5 \\
\hline A18 & 3 & 5 & 5 \\
\hline A19 & 4 & 5 & 5 \\
\hline A20 & 1 & 5 & 5 \\
\hline A21 & 1 & 5 & 5 \\
\hline A22 & 3 & 5 & 5 \\
\hline A23 & 4 & 3 & 5 \\
\hline A24 & 4 & 5 & 5 \\
\hline A25 & 3 & 5 & 5 \\
\hline A26 & 2 & 5 & 5 \\
\hline A27 & 1 & 5 & 5 \\
\hline A28 & 3 & 5 & 5 \\
\hline A29 & 3 & 5 & 5 \\
\hline A30 & 2 & 5 & 3 \\
\hline
\end{tabular}

Sumber: PT Smart Solution (2019)

\section{PEMBAHASAN}

Dalam pemilihan Karyawanteladan pada PT Smart Solution ada 30 Karyawan yang dinilai berdasarkan kriteria yang sudah ditetapkan yakni, 1) Penilaian Kinerja, 2) Masa Kerja, dan 3) Sikap Ada beberapa langkah untuk melakukan perhitungan dalam menentukan penentuan Karyawan teladan padaPT Smart Solution menggunakan metode Simple Additive Weighting, yaitu:

a) Menentukan kriteria penelitian (Ci) yang akan dijadikan acuan dalam menentukan pengambilan keputusan.

b) Menentukan bobot preferensi atau tingkat kepentingan (W) dari setiap kriteria.

c) Menentukan rating kecocokan setiap alternative pada setiap kriteria kemudian memodelkannya ke dalam bilangan fuzzy setelah dikonversikan kebilangan crips.

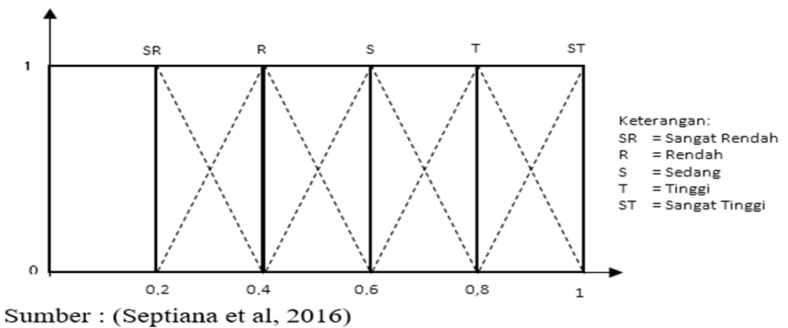

Gambar 1. Grafik Nilai Bobot Simple Additive Weighting 
Jurnal Inkofar * Volume 1 No. 2 Desember 2019 * ISSN: 2615-3645 (Print) / 2581-2920 (Online) Tersedia secara online di: http://www.politeknikmeta.ac.id/meta/ojs/

d) Membuat matriks keputusan berdasarkan kriteria (Ci)

$\left|\begin{array}{lll}4 & 1 & 5 \\ 3 & 1 & 5 \\ 5 & 1 & 5 \\ 1 & 5 & 5 \\ 1 & 5 & 5 \\ 5 & 1 & 5 \\ 4 & 1 & 5 \\ 4 & 3 & 5 \\ 5 & 1 & 4 \\ 5 & 5 & 5 \\ 5 & 1 & 5 \\ 5 & 1 & 5 \\ 2 & 5 & 5 \\ 1 & 3 & 5 \\ 4 & 5 & 3 \\ 5 & 5 & 4 \\ 2 & 5 & 5 \\ 3 & 5 & 5 \\ 4 & 5 & 5 \\ 1 & 5 & 5 \\ 1 & 5 & 5 \\ 3 & 5 & 5 \\ 4 & 3 & 5 \\ 4 & 5 & 5 \\ 3 & 5 & 5 \\ 2 & 5 & 5 \\ 1 & 5 & 5 \\ 3 & 5 & 5 \\ 3 & 5 & 5 \\ 2 & 5 & 3\end{array}\right|$

e) Melakukan normalisasi matriks berdasarkan jenis atribut (benefit \& cost).

\begin{tabular}{|ccc}
0,8 & 0,2 & 1 \\
0,6 & 0,2 & 1 \\
1 & 0,2 & 1 \\
0,2 & 1 & 1 \\
0,2 & 1 & 1 \\
1 & 0,2 & 1 \\
0,8 & 0,2 & 1 \\
0,8 & 0,6 & 1 \\
1 & 0,2 & 0,8 \\
1 & 1 & 1 \\
1 & 0,2 & 1 \\
1 & 0,2 & 1 \\
0,4 & 1 & 1 \\
0,2 & 0,6 & 1 \\
0,8 & 1 & 0,6 \\
1 & 1 & 0,8 \\
0,4 & 1 & 1 \\
0,6 & 1 & 1 \\
0,8 & 1 & 1 \\
0,2 & 1 & 1 \\
0,2 & 1 & 1 \\
0,6 & 1 & 1 \\
0,8 & 0,6 & 1 \\
0,8 & 1 & 1 \\
0,6 & 1 & 1 \\
0,4 & 1 & 1 \\
0,2 & 1 & 1 \\
0,6 & 1 & 1 \\
0,6 & 1 & 1 \\
0,4 & 1 & 0,8
\end{tabular}


Jurnal Inkofar * Volume 1 No. 2 Desember 2019 * ISSN: 2615-3645 (Print) / 2581-2920 (Online)

Tersedia secara online di: http://www.politeknikmeta.ac.id/meta/ojs/

f) Hasil akhir diperoleh dari proses penilaian Karyawan teladan yaitu penjumlahan dari perkalian ternormalisasi $\mathrm{R}$ dengan vector bobot sehingga diperoleh nilai terbesar yang dipilih sebagai alternative terbaik (Ai) sebagai solusi.

Tabel 6. Hasil Perhitungan SAW

\begin{tabular}{|c|c|c|}
\hline \multicolumn{3}{|c|}{ Kriteria } \\
\hline Alternatif (Karyawan) & Nilai & Prosentase \\
\hline $\mathrm{A} 1$ & 0,7 & 70 \\
\hline $\mathrm{A} 2$ & 0,6 & 60 \\
\hline $\mathrm{A} 3$ & 0,8 & 80 \\
\hline A4 & 0,6 & 60 \\
\hline A5 & 0,6 & 60 \\
\hline A6 & 0,8 & 80 \\
\hline A7 & 0,7 & 70 \\
\hline A8 & 0,8 & 80 \\
\hline A9 & 0,75 & 75 \\
\hline A10 & 1 & 100 \\
\hline A11 & 0,8 & 80 \\
\hline $\mathrm{A} 12$ & 0,8 & 80 \\
\hline A13 & 0,7 & 70 \\
\hline A14 & 0,5 & 50 \\
\hline A15 & 0,8 & 80 \\
\hline A16 & 0,95 & 95 \\
\hline A17 & 0,7 & 70 \\
\hline A18 & 0,8 & 80 \\
\hline A19 & 0,9 & 90 \\
\hline A20 & 0,6 & 60 \\
\hline A21 & 0,6 & 60 \\
\hline A22 & 0,8 & 80 \\
\hline A23 & 0,8 & 80 \\
\hline A24 & 0,9 & 90 \\
\hline A25 & 0,8 & 80 \\
\hline A26 & 0,7 & 70 \\
\hline A27 & 0,6 & 60 \\
\hline A28 & 0,8 & 80 \\
\hline A29 & 0,8 & 80 \\
\hline A30 & 0,6 & 80 \\
\hline
\end{tabular}

Sumber: PT Smart Solution (2019)

g) Hasil akhir diperoleh dari proses penilaian karyawan teladan yaitu yang telah dirangking.

Tabel 7. Hasil nilai berdasarkan rangking

\begin{tabular}{|c|c|c|}
\hline \multicolumn{3}{|c|}{ Kriteria } \\
\hline Alternatif (Karyawan) & Nilai & Prosentase \\
\hline $\mathrm{A} 10$ & 1 & 100 \\
\hline A16 & 0,95 & 95 \\
\hline A19 & 0,9 & 90 \\
\hline A24 & 0,9 & 90 \\
\hline $\mathrm{A} 3$ & 0,8 & 80 \\
\hline A6 & 0,8 & 80 \\
\hline A8 & 0,8 & 80 \\
\hline A11 & 0,8 & 80 \\
\hline $\mathrm{A} 12$ & 0,8 & 80 \\
\hline A15 & 0,8 & 80 \\
\hline A18 & 0,8 & 80 \\
\hline A22 & 0,8 & 80 \\
\hline A23 & 0,8 & 80 \\
\hline A25 & 0,8 & 80 \\
\hline A28 & 0,8 & 80 \\
\hline A29 & 0,8 & 80 \\
\hline $\mathrm{A} 30$ & 0,6 & 80 \\
\hline A9 & 0,75 & 75 \\
\hline $\mathrm{A} 1$ & 0,7 & 70 \\
\hline A7 & 0,7 & 70 \\
\hline $\mathrm{A} 13$ & 0,7 & 70 \\
\hline A17 & 0,7 & 70 \\
\hline A26 & 0,7 & 70 \\
\hline A2 & 0,6 & 60 \\
\hline A4 & 0,6 & 60 \\
\hline A5 & 0,6 & 60 \\
\hline A20 & 0,6 & 60 \\
\hline A21 & 0,6 & 60 \\
\hline A27 & 0,6 & 60 \\
\hline A14 & 0,5 & 50 \\
\hline
\end{tabular}

Sumber: PT Smart Solution (2019) 
Dari hasil perhitungan menggunakan metode Simple Additive Weighting mendapatkan nilai 100 dengan peringkat pertama diduduki oleh Dicky Taruna dan sekaligus menjadi Karyawan teladan di PT Smart Solution. Pada perhitungan dengan metode Simple Additive Weighting seluruh kriteria diberikan bobot, jadi jika ada kekurangan di salah satu kriteria tetapi bobotnya kecil maka tidak terlalu berpengaruh untuk penilaian, begitu juga sebaliknya jika bobot kriterianya besar tapi nilainya kecil maka akan sangat berpengaruh terhadap perangkingan.Jika dengan setiap cara biasa setiap kriteria tidak memiliki bobot sehingga jika ada nilai salah satu kriteria yang kecil masih bias di bantu dengan nilai lainnya, seandainya nilai pada keagamaan kecil tetapi hasil nilai rata-rata raport tinggi maka nilai keagamaan akan dipakai untuk nilai rata-rata raport, disinilah letak kekurangan penilaian metode yang lama.

\section{KESIMPULAN DAN SARAN}

\subsection{Kesimpulan}

Penentuan karyawan teladan dengan menggunakan metode Simple Additive Weighting sudah berjalan dengan baik dan dapat menghasilkan pembobotan kriteria penilaian dan informasi yang jelas dan akurat sehingga PT Smart Solutiondapat mempergunakannya sebagai alat bantu dalam pengambilan keputusan yang tepat untuk menetapkan Karyawan teladan.

Kriteria pada data yang ada untuk penentuan Karyawan teladan sudah bersifat objektif dikarenakan menggunakan metode Simple Additive Weighting dimana jika bobot kriteria besar tetapi nilainya kecil akan sangat berpengaruh untuk penilaian, tetapi jika ada kekurangan pada salah satu kriteria yang bobotnya kecil maka tidak terlalu berpengaruh untuk penilaian.

\subsection{Saran}

Untuk meningkatkan sistem pendukung keputusan pada PT Smart Solution perlu adanya perbandingan dengan menambahkan sebuah aplikasi yang berbasis komputer sehingga sistem pendukung keputusan karyawan teladan lebih cepat.

\section{DAFTAR PUSTAKA}

Dessler, Gary (2005). Manajemen Sumber Daya Manusia, Edisi 10, terjemahan, Salemba Empat Latif, Lita Asyriati, Mohamad Jamil, dan Said HI Abbas. 2018. Sistem PendukungKeputusan Teori dan Implementasi.Yogyakarta: DEEPUBLISH.

Mulyani, Evi Dewi Sri. Yoga Handoko Agustin dan Sri Fitria Kamellia. (2015). Sistem Pendukung Keputusan Siswa Teladan Menggunakan Metode Simple Additive (Studi Kasus : Di Smp Negeri 3 Tasikmalaya). Seminar Nasional Informatika. 38-44.

Nofriansyah, Dicky. (2014). Konsep Data Mining vs Sistem Pendukung Keputusan. Yogyakarta: Deepublish.

Anita Siandar RMS, Jamal Purba "Penentuan Karayawan Lembur Dengan Metode AnalyticalHierarchy Process (Ahp)"Jurnal Inkofar * Volume 1 No. 2, Desember 2018 * ISSN: 2615-3645 (Print) / 2581-2920 (Online)Tersedia secara online di: http://www.politeknikmeta.ac.id/meta/ojs/

Rina Endarti, Andriani Kusumaningrum, Wawan Laksito YS "PENERAPAN METODE SIMPLE ADDITIVE WEIGHTING DALAM MENGEVALUASI KINERJA KARYAWAN UNTUK MEMILIH KARYAWAN TELADAN DI PT. SRITEX, TBK (DEPT. SPINNING V) SUKOHARJO

Saefudin, Sri Wahyuningsih "Sistem Pendukung Keputusan Untuk Penilaian Kinerja Pegawai Menggunakan Metode AnalyticalHierarchy Process (Ahp) Pada RSUD Serang" Jurnal Sistem Informasi Vol- 1 No.1 2014 ISSN: 2406-7768"

Sutabri, Tata. 2012. Konsep Sistem Informasi. Yogyakarta: ANDI. 